\title{
Basic fibroblast growth factor lentiviral vector-transfected sheep bone marrow mesenchymal stem cells and non-specific osteogenic gene expression
}

\author{
YANG HU, QIN ZHANG ${ }^{*}$, LEI ZHANG ${ }^{*}$, XIAO-XUE TANG and HUI-YU HE \\ Department of Prosthodontics, The First Affiliated Hospital of Xinjiang Medical University, \\ Wulumuqi, Xinjiang 830054, P.R. China
}

Received April 20, 2014; Accepted January 7, 2015

DOI: $10.3892 / \mathrm{mmr} .2015 .3399$

\begin{abstract}
In the present study, sheep bone marrow stem cells (BMSCs) were transfected with basic fibroblast growth factor (bFGF)-lentivirus in order to investigate the influence of bFGF on osteogenic gene expression. bFGF-transfected BMSCs (experimental group) and non-transfected BMSCs (control group) were also transfected with a green fluorescent protein gene in order to measure the transfection efficiency of the (bFGF)-lentivirus using flow cytometry. Using quantitative polymerase chain reaction assays, the changes in expression from three genes (osteopontin, OPN; osteocalcin, OC; and collagen-I) in BMSCs from the experimental and control groups were measured. Transfection efficiency was $87.3 \%$ in the experimental group and $1.1 \%$ in the control group. OPN gene expression was high in BMSCs from the experimental group. However, there was no significant difference in OPN expression between BMSCs from the control and experimental group $(\mathrm{P}>0.05)$. Collagen-I expression was significantly lower in the experimental group compared with that in the control groups $(\mathrm{P}<0.05)$. By contrast, $\mathrm{OC}$ expression was significantly higher in BMSCs from the experimental group compared with that in the control group $(\mathrm{P}<0.05)$. Changes in osteogenic gene expression indicated that the BMSCs from the experimental group had better osteogenic ability, as compared with the control cells. Therefore, bFGF-transfected cells may be useful seed cells for bone tissue engineering.
\end{abstract}

Correspondence to: Dr Hui-Yu He, Department of Prosthodontics, The First Affiliated Hospital of Xinjiang Medical University, 137 Liyushan South Road, Wulumuqi, Xinjiang 830054, P.R. China E-mail: hehuiyu02@sina.com

${ }^{*}$ Contributed equally

Key words: bone marrow mesenchymal stem cells, basic fibroblast growth factor, lentivirus, sheep, osteoblasts

\section{Introduction}

Basic fibroblast growth factor (bFGF) is a member of the fibroblast growth factor family. It is involved in cell mitosis, proliferation and differentiation (1). Studies have shown that bFGF is capable of promoting osteoblast cell mitosis and is also involved in the regulation of osteoblast phenotypes and the expression of extracellular matrix-related genes. bFGF is also involved in gene expression and blood vessel formation $(1,2)$. Therefore, it is important in the process of bone tissue repair. Lentiviral vectors are capable of accommodating larger exogenous genes compared with plasmid vectors. Lentiviral vectors may also be used in conjunction with antibiotics for screening transfected cells and are capable of long-term stable gene expression. Lentiviral vectors are capable of infecting dividing and non-dividing cells. Typically, the immunoreactive effects of lentiviral vectors are small (3). In the present study, in order to examine the osteogenic capability of sheep bone marrow mesenchymal stem cells (BMSCs), lentiviral vectors carrying the human bFGF gene were transfected into BMSCs.

\section{Materials and methods}

Experimental materials. One Shot Stbl3 ${ }^{\mathrm{TM}}$ Chemically Competent Escherichia coli cell kits, pLenti6/V5-D-TOPO vector of lentiviral eukaryotic expression, and lentiviral packaging plasmids, pLP, pLP2 and $\mathrm{pLP} / \mathrm{VSVG}$, were obtained from Invitrogen Life Technologies (Carlsbad, CA, USA). Lipofectamine $2000^{\circledR}$ liposome transfection reagent, the 293-FT cell line, ampicillin, lysogeny broth (LB) solid medium and super optimal broth were also obtained from Invitrogen Life Technologies. An efficient competent cells kit was obtained from Shanghai Sangon Biological Engineering Technology \& Services Co., Ltd. (Shanghai, China). A large agarose gel DNA extraction kit was obtained from Omega bio-tek (Norcross, GA, USA). A high purified small plasmid middle quantity kit was obtained from Tiangen Biotech (Beijing, China). A RevertAid ${ }^{\mathrm{TM}}$ First Strand cDNA Synthesis kit and Premix Ex Taq were obtained from Fermentas (Vilnius, Lithuania). Pfu DNA Polymerase (recombinant), geneticin and blasticidin antibiotics were obtained from Gibco-BRL (Invitrogen Life Technologies). 
Table I. Osteoblast gene expression in BMSCs of the experimental and control groups.

\begin{tabular}{lcccr}
\hline Osteoblast gene & Control group & Experimental group & t-test & P-value \\
\hline Osteopontin & $18.37 \pm 1.05$ & $19.10 \pm 1.14$ & -0.08 & 0.94 \\
Osteocalcin & $0.35 \pm 0.04$ & $0.69 \pm 0.04$ & -16.82 & 0.00 \\
Collagen-I & $27465.12 \pm 833.12$ & $9517.54 \pm 191.18$ & 36.37 & 0.00
\end{tabular}

BMSCs, bone marrow mesenchymal cells; experimental group, bFGF-transfected BMSCs; control group, non-transfected BMSCs.

bFGF-plenti6/V5 plasmid and green fluorescent protein (GFP)-plenti6/V5 plasmid were generated in our laboratory. The human bFGF and GFP genes was cloned into the plenti6/V5 plasmid using Pfu DNA polymerase (in High Purity Plasmid Minipure kit; Tiangen Biotech) and polymerase chain reaction (PCR). The bFGF-plenti6/V5 and GFP-plenti6/V5 plasmids were transformed into One Shot Stbl3TM Chemically Competent Escherichia coli cells. The Stbl3 cells were cultured with $100 \mu \mathrm{g} / \mathrm{ml}$ ampicillin for $20 \mathrm{~h}$, then the cells were split and the plasmids were extracted. The bFGF-plenti6/V5 and GFP-plenti6/V5 plasmids were then sequenced and it was confirmed that they did not contain frameshift mutations.

Experimental apparatus. The following apparatus was used: $\mathrm{CO}_{2}$ constant temperature incubator and biological safety cabinet from Thermo Fisher Scientific (Waltham, MA, USA); a centrifuge from Jouan (Nantes, France); an IX71 inverted fluorescence microscope from Olympus, (Tokyo, Japan); a UV spectrophotometer from Bio-Rad (Hercules, CA, USA); an Epics Altra flow cytometer from Beckman-coulter (Carlsbad, CA, USA); an HHS-type electric heated water bath from Cloud Vision Networks Technology Co., Ltd. (Shanghai, China); an ABI Veriti gradient polymerase chain reaction instrument from Applied Biosystems Life Technologies (Foster City, CA, USA); a gel imager and the IQ5 quantitative PCR (qPCR) instrument from Bio-Rad; and a constant temperature shaker and a refrigerated centrifuge were obtained from Eppendorf (5810 R; Hamburg, Germany). The present study was approved by the Ethics Committee of Animal Management of The First Affiliated Hospital of Xinjiang Medical University (Wulumuqi, China).

Method of culture and generation of BMSCs. The Altay tailed sheep (obtained from the Animal Management Centre of Xinjiang Medical University, Wulumuqi, China) was anesthetized by intramuscular injection of $0.9 \mathrm{ml} 10 \%$ chloral hydrate (Sangon Biotech Co. Ltd., Shanghai, China) and $0.6 \mathrm{ml} \mathrm{diaz-}$ epam (Tianjin Jinyao Amino Acid Co., Ltd., Shanghai, China) and sacrificed by injection of $90 \mathrm{mg} / \mathrm{kg}$ pentobarbital. The limbs were mobilized, the surgical area shaved, and routine disinfection and draping were performed. A bone marrow cavity puncture was performed at the posterior superior iliac spine. A total of $10 \mathrm{ml}$ of bone marrow was collected and placed separately in centrifuge tubes labeled A and B, which contained $200 \mathrm{U} / \mathrm{ml}$ heparin (Sangon Biotech Co. Ltd.). After thorough mixing the $5 \mathrm{ml}$ bone marrow in each tube was filtered through 200-mesh stainless steel microporous filters
(Dun qi Filtration Equipment Company, Shanghai, China), diluted with $10 \mathrm{ml}$ Dulbecco's modified Eagle's medium/F12 supplemented with $10 \%$ fetal bovine serum, $1 \times 10^{-8} \mathrm{mM}$ dexamethasone, $0.01 \mathrm{mM}$ sodium $\beta$-glycerophosphate, $0.05 \mathrm{~g} / 1$ vitamin C, $100 \mathrm{U} / 1$ penicillin, and $100 \mathrm{U} / 1$ streptomycin (v/v; Invitrogen Life Technologies), and inoculated into $25 \mathrm{~cm}^{2}$ culture flasks. After three days half of the culture medium was refreshed. All of the medium was refreshed after seven days, after which the medium was refreshed every three days. The cells were passaged at a 1:3 ratio, once they were $80-90 \%$ confluent. The vitality and growth of the cells was observed daily using an IX71 inverted fluorescence microscope.

Transformation step. Competent E. coli cells (1x10 $/ \mathrm{ml})$ were melted on ice. Subsequently, bFGF-plenti6/V5 vector $(2 \mu \mathrm{l}$; $2 \mu \mathrm{g} / \mu \mathrm{l})$ and GFP-plenti6/V5 vector $(2 \mu \mathrm{l} ; 2 \mu \mathrm{g} / \mu \mathrm{l})$ were added, and mixed using a pipette. Cells were then placed on ice and incubated for $30 \mathrm{~min}$. Subsequently, they were incubated at $42^{\circ} \mathrm{C}$ for $90 \mathrm{sec}$, and then placed on ice for $2 \mathrm{~min}$. Super optimal broth $(250 \mu \mathrm{l})$ was added and the mixture was shaken horizontally at $300 \mathrm{rpm}$ at $37^{\circ} \mathrm{C}$ for $1 \mathrm{~h}$. Following disinfection for 30 min using UV light, a glass rod was used to place $35-50 \mu 1$ of bacteria uniformly onto a petri dish containing a solid medium (100 $\mu \mathrm{g} / \mathrm{ml}$ ampicillin). The plates were inverted and incubated at $37^{\circ} \mathrm{C}$ in $5 \% \mathrm{CO}_{2}$ overnight. The following day 10-100 colonies were visible per plate. Between five and ten positive colonies were selected using an inoculating loop (Shanghai Sangon Biological Engineering Technology \& Services Co., Ltd.) and placed into a centrifuge tube containing LB liquid $(5 \mathrm{ml})$. Samples were horizontally shaken at $300 \mathrm{rpm}$ at $37^{\circ} \mathrm{C}$ in an incubator overnight.

Lentiviral vector and transfection. bFGF-lentiviral vector establishment was conducted according to the manufacturer's instructions (ViraPower ${ }^{\mathrm{TM}}$ Lentiviral Expression Systems; Invitrogen Life Technologies). Viral supernatants (1 ml) were collected for cryopreservation at $-80^{\circ} \mathrm{C}$. A GFP lentiviral vector establishment method was conducted according to bFGF-lentiviral vector establishment.

GFP lentiviral vector transfection efficiency detection using flow cytometry. GFP lentiviral vector-transfected sheep BMSCs $\left(500 \mu \mathrm{l} ; 1 \times 10^{6} / \mathrm{ml}\right)$ were placed into three tubes (experimental groups). Non transfected BMSCs $\left(500 \mu \mathrm{l} ; 1 \times 10^{6} / \mathrm{ml}\right)$ were collected and placed into one tube (control group). The cells then underwent flow cytometry (Beckman Coulter, Brea, CA, USA). The detection of GFP lentiviral transfection efficiency was repeated three times. 


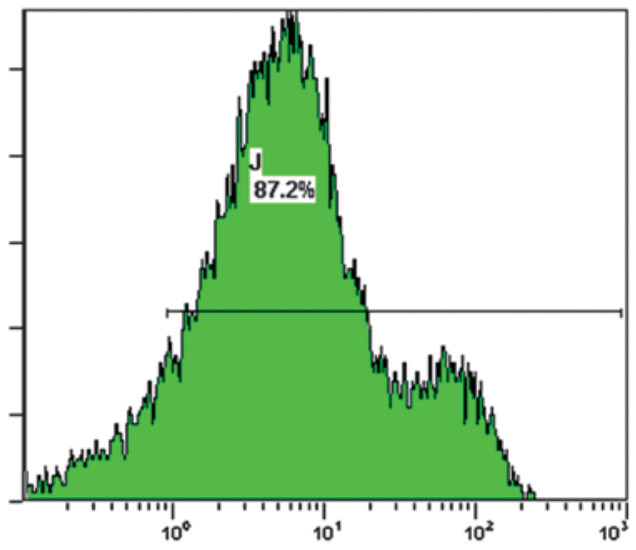

Figure 1. Green fluorescent protein lentiviral vector transfected group. J, transfection efficiency.

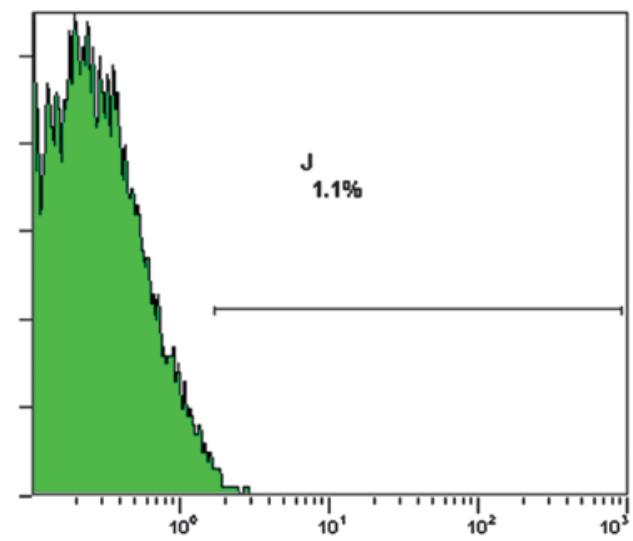

Figure 2. Green fluorescent protein non-transfected group. J, transfection efficiency.

qPCR. Primers were designed and synthesized by Takara Bio (Dalian, China), The following primers were used: Forward: 5'-CAGAGGCACCACATGACCAC-3' and reverse: 5'-CGAGTGAGCGAAAGACAGCA-3' for osteopontin (OPN), forward: 5'-GATGCAGAGTCGGGCAAAG-3' and reverse: 5'-AGCTCACACACCTCCCTCCT-3' for osteocalcin (OC), forward: 5'-ACCTACCACTGCAAGAACAGCG-3' and reverse: 5'-AAGCAGACAGAGCCGATGTTCG-3' for collagen-I and forward: 5'-GGCTC CTTCCAGCCTTCCT-3' and reverse: 5'-ATGCC AGGGTACATGGTGGT-3' for the reference gene, $\beta$-actin. The PCR reaction $(20 \mu \mathrm{l})$ contained Premix Ex Taq $(10 \mu \mathrm{l})$, cDNA $(1 \mu \mathrm{l})$, primers $(1 \mu \mathrm{l} ; 10 \mathrm{pmol} / \mu \mathrm{l})$, and $\mathrm{ddH}_{2} \mathrm{O}(8 \mu \mathrm{l})$. The PCR protocol for the amplification of OPN, OC and $\beta$-actin was: $95^{\circ} \mathrm{C}$ for $3 \mathrm{~min}$, followed by 40 cycles of $95^{\circ} \mathrm{C}$ for $10 \mathrm{sec}$ and $58^{\circ} \mathrm{C}$ for $30 \mathrm{sec}$. The PCR protocol for the amplification of collagen-I was: $95^{\circ} \mathrm{C}$ for $3 \mathrm{~min}$, followed by 40 cycles of $95^{\circ} \mathrm{C}$ for $10 \mathrm{sec}$ and $64^{\circ} \mathrm{C}$ for $30 \mathrm{sec}$. The results of qPCR were quantified according to standard and solubility curves, with the $\Delta \Delta \mathrm{Ct}$ method and CFX 96 (Bio-Rad).

Statistical methods. SPSS, Inc., 17.0 (Chicago, IL, USA) was used for statistical analysis. Continuous data are expressed as the mean \pm standard deviation and paired t-tests were performed to compare independent samples. $\mathrm{P}<0.05$ was considered to indicate a statistically significant difference.

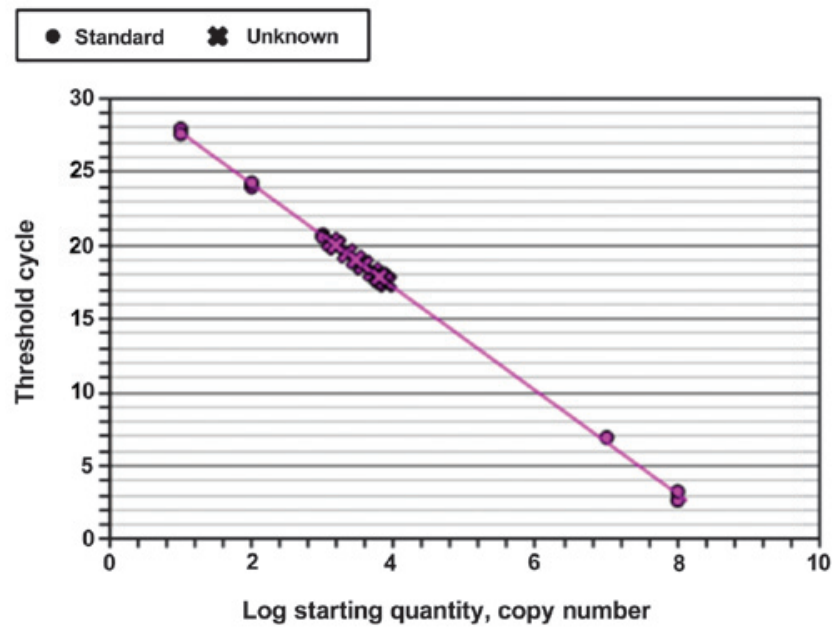

Figure 3. Standard curve of osteopontin. The results are taken from the bone marrow stem cells transfected with the basic fibroblast growth factor-lentiviral vector.

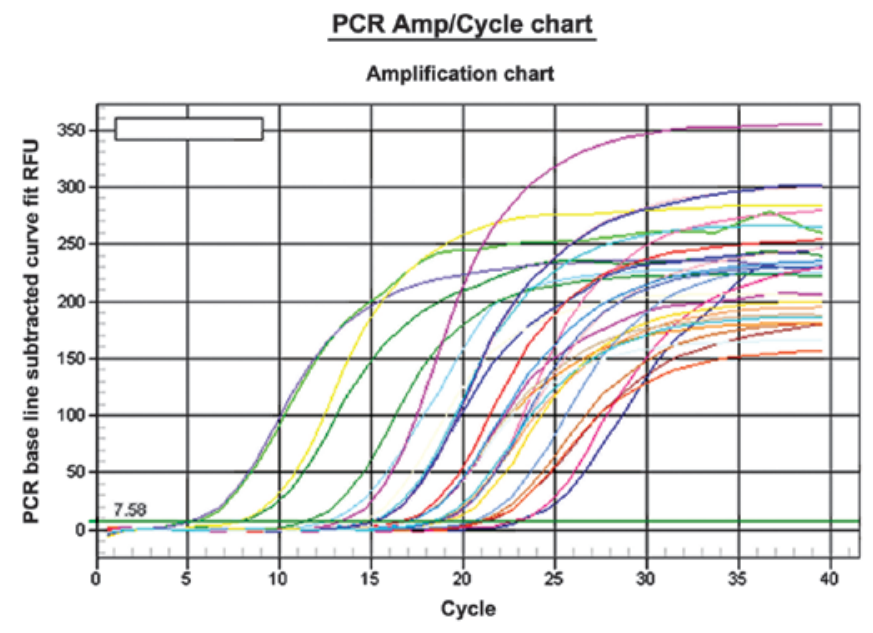

Figure 4. Amplification curve of osteopontin. The results are taken from the bone marrow stem cells transfected with the basic fibroblast growth factor-lentiviral vector. PCR, polymerase chain reaction; Amp, amplification.

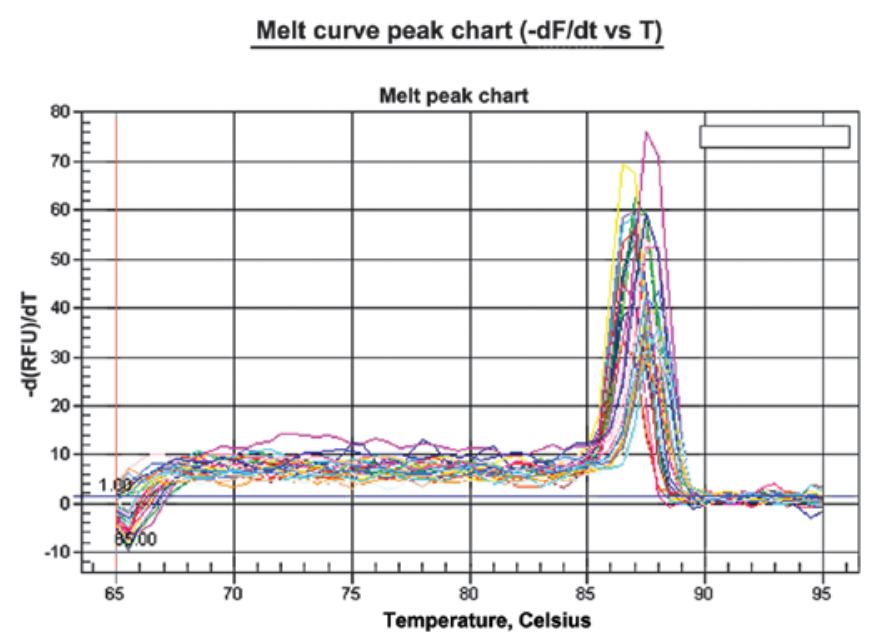

Figure 5. Dissolution curve of osteopontin. The results are taken from the bone marrow stem cells transfected with the basic fibroblast growth factor-lentiviral vector. 


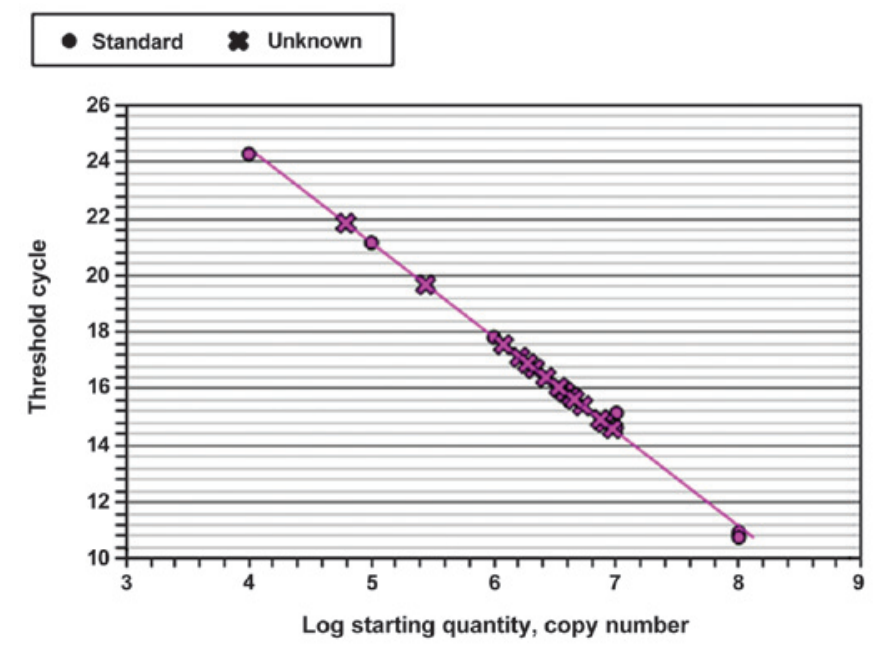

Figure 6. Standard curve of Collagen-I. The results are taken from the bone marrow stem cells transfected with the basic fibroblast growth factor-lentiviral vector.

\section{PCR quantification data}

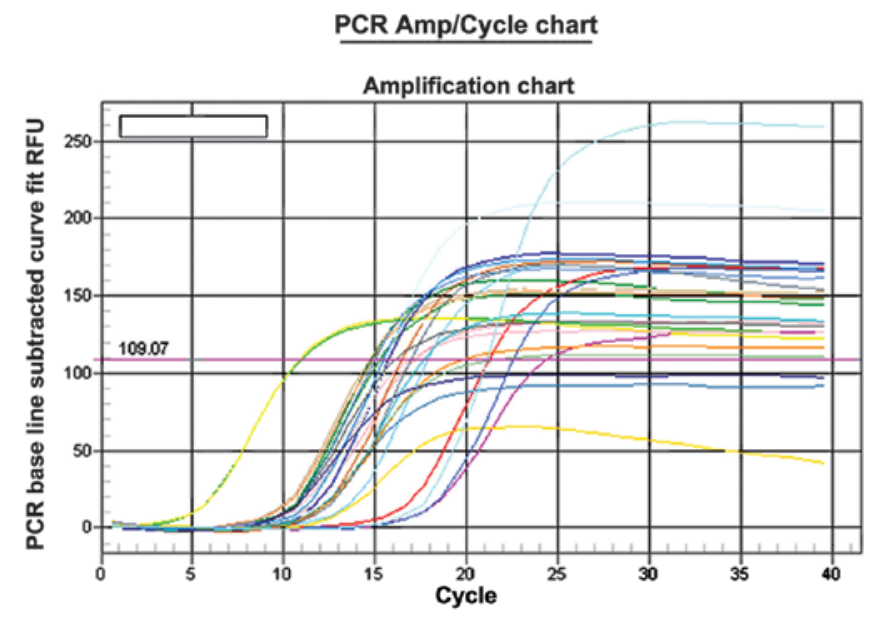

Figure 7. Amplification curve of Collagen-I. The results are taken from the bone marrow stem cells transfected with the basic fibroblast growth factor-lentiviral vector. PCR, polymerase chain reaction; Amp, amplification.

\section{Melt curve peak chart (-dF/dt vs T)}

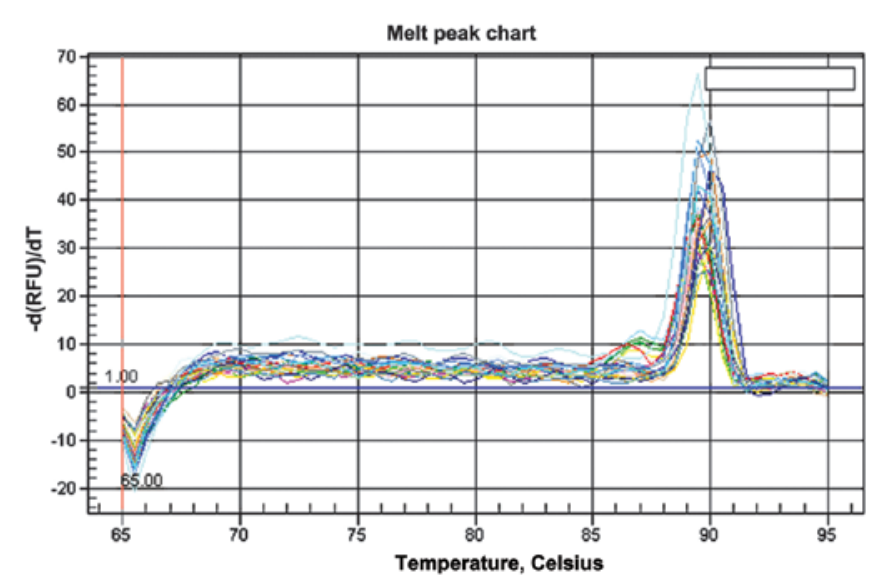

Figure 8. Dissolution curve of Collagen-I The results are taken from the bone marrow stem cells transfected with the basic fibroblast growth factor-lentiviral vector.

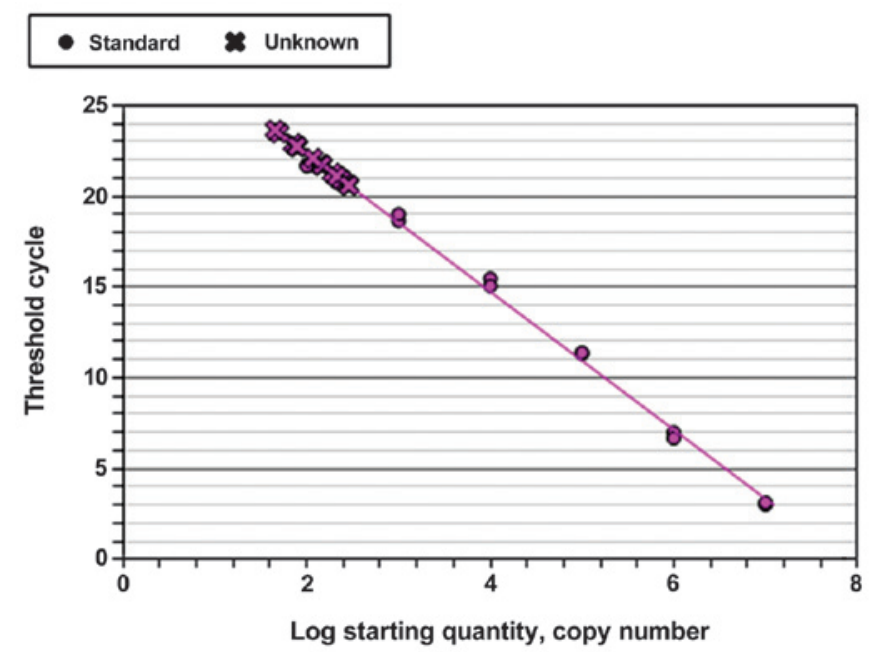

Figure 9. Standard curve of osteocalcin. The results are taken from the bone marrow stem cells transfected with the basic fibroblast growth factor-lentiviral vector.

\section{PCR quantification data}

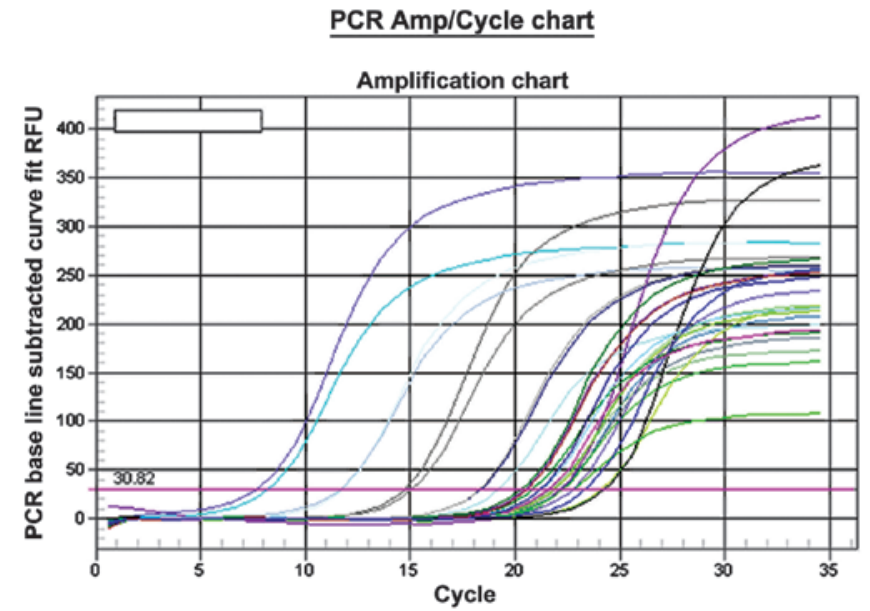

Figure 10. Amplification curve of osteocalcin. The results are taken from the bone marrow stem cells transfected with the basic fibroblast growth factor-lentiviral vector. PCR, polymerase chain reaction; Amp, amplification.

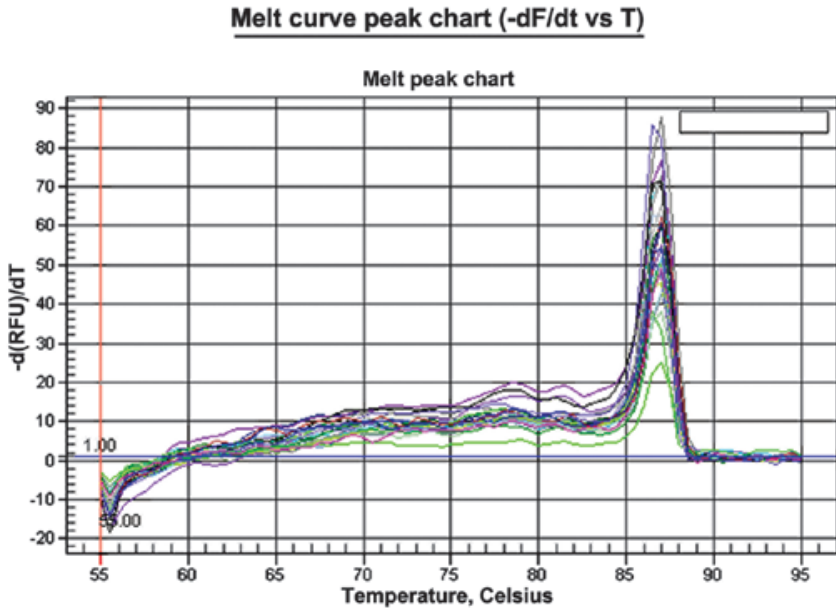

Figure 11. Dissolution curves of osteocalcin. The results are taken from the bone marrow stem cells transfected with the basic fibroblast growth factor-lentiviral vector. 


\section{Results}

Flow cytometry detection. The transfection efficiency was $87.2 \%$ in the experimental groups (bFGF-lentiviral vector-transfected BMSCs) and $1.1 \%$ in the control group (non-transfected BMSCs) according to flow cytometry analysis (Figs. 1 and 2).

Effects of bFGF-lentiviral transfection on osteogenic gene expression in BMSCs. Changes in OPN, OC and Collagen-I mRNA expression in fourth generation BMSCs from the experimental and control groups were measured. Collagen-I gene expression in the experimental group was significantly lower compared with that in the control group $(\mathrm{P}<0.05)$. By contrast, OC gene expression in the experimental group was significantly higher than that in the control group $(\mathrm{P}<0.05)$. OPN gene expression levels showed no significant difference between BMSCs from the experimental and control groups $(\mathrm{P}>0.05$; Table I).

Standard curve, amplification curve and dissociation curve of osteogenic genes using qPCR. There was no significant difference between the gene expression levels of OPN in the experimental group and the control group (Figs. 3, 4 and 5). The gene expression levels of collagen-I were lower in the experimental group, as compared with the control group (Figs. 6, 7 and 8). OC gene expression levels in the experimental group were significantly higher, as compared with the control group (Figs. 9, 10 and 11).

\section{Discussion}

Studies have demonstrated that bFGF stimulates the proliferation of fibroblasts $(4,5)$. It is involved in promoting the formation of new capillaries, and in the repair of soft tissue, cartilage, bone and nerve (6). bFGF is involved in osteogenesis; it induces cell differentiation into osteoblasts, in addition to promoting angiogenesis. Previous studies have suggested that bFGF may promote the proliferation of bone marrow stromal cells and that it may be involved in the proliferation and maintenance of osteoblasts $(4,7,8)$. Furthermore, bFGF is a potent mitogen (4).

The lentivirus vector is a type of RNA retroviral vector that is capable of infecting non-dividing and dividing cells and accommodates large exogenous gene fragments and long-term stable gene expression. Furthermore, the immunoreactive effects of lentiviral vectors are small. Zhang et al (9) used a Vira Power lentiviral vector system in order to investigate the effects of bFGF on meniscal fibrocartilage cell injury in white rabbits from New Zealand. Following 48 h of transfection, the expression of bFGF in the meniscus cells had increased significantly, and bFGF promoted cell proliferation and matrix synthesis. Numerous studies have demonstrated that lentiviral vectors are capable of transfecting genes, which are difficult to transfect with other types of vectors. Indraccolo et al (10), demonstrated that the transfection efficiency of lentiviral vectors was ten times greater than that of retroviral vectors. Furthermore, in ovarian cancer gene therapy in vivo, expression efficiency was nearly 100 times greater in lentiviral vectors compared with retroviral vectors (10).
qPCR is a nucleic acid quantification method, which was developed at the end of the 20th century. Its advantages include high specificity, sensitivity, accuracy and reproducibility, and wide quantitative range. In addition, it is non-polluting and has short operation times $(11,12)$. Therefore, $\mathrm{qPCR}$ is useful in medicinal (13), food (14), animal (15-20) and microbiological (21) research. It is the most commonly used method for studying gene expression and for pathogen identification.

To the best of our knowledge, there have been limited investigations into osteoblast gene expression using qPCR. Therefore, the results of the present study are useful for understanding osteogenic-related gene expression patterns and the process underlying the differentiation of BMSCs into osteogenic cells. Runt-related transcription factor 2 (Runx2) protein is a transcription factor that is associated with osteoblast differentiation (22). It is involved in the regulation of multiple signaling pathways that are active in osteoblast differentiation. Kim et al (22) demonstrated that bFGF is involved in osteoblast differentiation by regulating Runx 2 activity. FGF/FGF-receptor signaling promoted Runx 2 transcription activity and protein expression via the protein kinase C pathway. Xiao et al (23), demonstrated that bFGF is involved in the regulation of Runx 2 activity and OC gene expression. bFGF promoted the OC mRNA expression and promoter activity in the rat osteoblast-like cell line, MC3T3-E1, in a dose- and time-dependent manner. bFGF phosphorylation and Runx2 activation was achieved via ERK1/2 signaling pathways. Teplyuk et al (24) demonstrated that Runx 2 molecular pathways regulate the expression of certain osteoblast genes, including OPN and alkaline phosphatase, enhance cell proliferation and promote the differentiation of BMSCs into osteogenic cells.

The results of the present study suggested that collagen-I expression was significantly lower, and OC expression was significantly higher, in BMSCs from the experimental group compared with those in the control group. These observations may be explained by the slow differentiation process of BMSCs into osteogenic cells in the mineralized induction medium. It is possible that the cultured cells did not reach mineralization maturity. The results of the present study suggest that in the experimental group, bFGF may have accelerated the differentiation of BMSCs into osteoblasts, causing the transfected cells to secrete bFGF, which may have promoted OC gene expression.

A number of studies have demonstrated that OC gene expression is an important indicator for maturity of bone cells. The expression of collagen-I, OPN and OC was measured in fourth generation BMSCs. In BMSCs in the experimental group, collagen-I expression was the lowest and that of OC was the highest. Therefore, cells in the experimental group appear to have been closer to mineralization maturity than cells in the control group. bFGF therefore exhibited a regulatory role in associated gene and protein expression involved in BMSC differentiation.

The majority of research on bone tissue engineering has focused on growth factor-induced cells and gene transfection-induced cells. Studies have investigated the differentiation of BMSC differentiation into osteogenic cells by measuring cell proliferation, matrix maturity and mineralization maturity. The expression of non-specific osteoblasts genes, such as OPN, collagen-I and OC have been examined. However, to the 
best of our knowledge, there have been limited studies on the quantification of non-specific osteogenic gene expression.

The present study quantified bone-related gene expression at different stages of BMSC differentiation (25), which is beneficial for understanding gene transfection and expression patterns involved in the differentiation of BMSCs into osteogenic cells. The present study has demonstrated that bFGF-transfected BMSCs exhibit a number of osteogenic functions and that bFGF regulates the expression of certain osteongenic genes. Therefore, they may be useful seed cells for bone tissue engineering.

\section{Acknowledgements}

The present study was supported by the National Natural Science Fund Project, topic: 3D Printing Construct Tissue-Engineered Alveolar Bone of the Experimental Research (grant no. 81060088); Experimental Study of Three-Dimensional Printing Protein Composite Ceramic Bone and its Repairing Ability of Mandibular Defect (grant no. 2014211C03); and The First Affiliated Hospital of Xinjiang Medical University Tissue Engineering Special Fund (Tooth Tissue Engineering Scaffold Materials Binder Modified and Mechanical Properties of Experimental Research; grant no. 2012ZZGC01).

\section{References}

1. Bai Y, Li P, Yin G, et al: BMP-2, VEGF and bFGF synergistically promote the osteogenic differentiation of rat bone marrow-derived mesenchymal stem cells. Biotechnol Lett 35: 301-308, 2013

2. Murakami S: Peridontal tissue regeneration by signaling molecule(s): what role does basic fibroblast growth factor (FGF-2) have in peridontal therapy? Peridontol 2000 56: 188-208, 2011.

3. Cockrell AS and Kafri T: Gene delivery by lentivirus vectors. Mol Biotechnol 36: 184-204, 2007.

4. Kotev-Emeth S, Pitary S,Pri-Chen S, and Savion N: Establishment of a rat long-term culture expressing the osteogenic phenotype: dependence on dexamethasone and FGF-2. Connect Tissue Res 43: 606-612, 2002.

5. Hu yang, Ma Ying and He Huiyu. The construction of eukaryotic expression lentiviral vector with basic fibroblast growth factor and transfection. Zhongguo zu zhi gong cheng yan jiu yu lin chuang kang fu za zhi 15: 1009-1014, 2011 (In Chinese).

6. Farhadi J, Jaquiery C, Barbero A et al: Differentiation-dependent up-regulation of BMP-2, TGF-beta1 and VEGF expression by FGF-2 in human bone marrow stromal cells. Plast Reconstr Surg 116: 1379-1386, 2005.

7. Wang L, Pang KF, Huang YL and Zhang XL: Experimental study of effects of different concentrations of bFGF proliferation and differentiation of canine bone marrow stromal cells. Kouqiang he mian wai ke za zhi 18: 6-10, 2008 (In Chinese).

8. Locklin RM, Oreffo RO and Triffitt JJ: Effects of TGFbeta and bFGF on the differentiation of human bone marrow stromal fibroblasts. Cell Biol 23: 185-194, 1999.
9. Zhang JW, Feng JX, Xu RM, Zhao JZ and Zeng BF: Slow virus mediated alkaline fibroblast growth factor gene transfection meniscal fibrocartilage cells proliferation and matrix synthesis. Zhongguo zu zhi gong cheng yan jiu yu lin chuang kang fu za zhi 11: 8267-8270, 2007 (In Chinese).

10. Indraccolo S, Habeler W, Tisato V, Stievano L, Piovan E, Tosello V, Esposito G, Wagner R, Uberla K, Chieco-Bianchi L and Amadori A: Gene transfer in ovarian cancer cells: a comparison between retroviral and lentivial vectors. Cancer Res 62: 6009-6107, 2002.

11. Wong LJ and Bai RK: Real-time quantitative polymerase chain reaction analysis of mitochondrial DNA point mutation. Methods In Mol Biol 335: 187-200, 2006.

12. Schmittgen TD: Real-time quantitative PCR. Methods 25: 383-385, 2001.

13. Liu XR, Zhang L and Wang YP: The theoretical research of real-time fluorescent quantitative PCR technology and medical applications. Zhongguo zu zhi gong cheng yan jiu yu lin chuang kang fu za zhi 14: 329-332, 2010 (In Chinese).

14. Li YX, Li ZT and Wang YL: Real-time fluorescent quantitative PCR in the field of food testing applications. Liangshi yu you zhi za zhi 2: 38-40, 2010 (In Chinese).

15. Chen X, Qi FK and Kang LG, et al: Real-time fluorescent quantitative research progress and application technology. Dongbei nong ye da xue xue bao za zhi 41: 148-155, 2010 (In Chinese).

16. Tu LL, Zhang XL and Liu DQ, et al: In cotton fiber development and process of somatic embryogenesis in implementing control gene screening. Kexue tong bao za zhi. 52: 2379-2385, 2007 (In Chinese).

17. Yu SW, Liu HY, Luo LJ: Analysis of relative gene expression using different real-time quantitative PCR. Acta Agron Sin 33: 1214-1218, 2007 (In Chinese).

18. Wei M, Xiong JH, Li YS and Fu BY: Study on glycogen synthase kinase gene expression variation under drought stress in rice by real-time PCR. Chinese Journal of Rice Science 20: 567-571, 2006 (In Chinese).

19. Wang Q, Huang C, Zhang ZB, Hu JY and Zhang RZ: Real-time quantitative RTPCR method detection primitive culture medaka oestrogen induced fish liver cell gene expression. Huanjing ke xue xue bao za zhi 28: 2568-2572, 2008 (In Chinese).

20. Zhang SB, Zhao YS, Liu X, Wang C and Liu GQ: Real-time quantitative PCR detection peas II etiolation seedling of actin isoforms expression. Beifang yuan yi za zhi 110-113, 2010 (In Chinese).

21. Wei XX, Li XZ, Tong GX and Wu XQ: Real-time fluorescent quantitative PCR technique and its application in aquatic animal viral disease quantitative detection. Shuichan ke xue za zhi 29: 681-686, 2010 (In Chinese).

22. Kim HJ, Park HD, Kim JH, Cho JY, Choi JY, Kim JK, Kim HJ, Shin HI and Ryoo HM: Establishment and characterization of a stable cell line to evaluate cellular Runx2 activity. J Cel Biochem 91: 1239-1247, 2004.

23. Xiao G, Jiang D, Gopalakrishnan R and Franceschi RT: Fibroblastgrowth factor 2 induction of the osteocalcin gene requires MAPK activity and phosphorylation of the osteoblast transcription factor, Cbfa1/Runx2. J Biol Chem 277: 36181-36187, 2002.

24. Teplyuk NM, Haupt LM, Ling L, et al: The osteogenic transcription factor Runx 2 regulates components of the fibroblast growth factor/proteoglycan signaling axis in osteoblasts. J Cell Biochem 107: 144-154, 2009.

25. Cotter EJ, Ip HS, Powderly WG and Doran PP: Mechanism of HIV protein induced modulation of mesenchymal stem cell osteogenic differentiation. BMC Musculoskelet Disord 9: 33, 2008 . 